\title{
A Rapid Method for Reliability Analysis of Composite Tophat Stiffened Structures using a First Principles Method and Design Rules
}

\author{
A.J.Sobey, $\quad$ J.I.R.Blake, \\ R.A.Shenoi \\ University of Southampton, University Road, Southampton, UK, SO17 1BJ
}

September 3, 2013

\begin{abstract}
Composite materials are increasingly being used within engineering, especially in low weight applications. A significant drawback that these materials exhibit is their variability. There is a growing trend towards stochastic analysis of marine structures and this is even more important for scenarios that have a high variability. To implement these new techniques it is important to be able to, rapidly and accurately, determine reliability during the design phase. Therefore, a reliability analysis, utilising a rapid implementation, has been performed on plates that have been designed using two different sets of design rules and a first principles method. The results show that whilst, under the limits investigated, the reliability of the design rules are slightly safer than those found using first principles; the sensitivity analysis shows that each of the design rules generates a different reaction from each variable, encouraging different types of structures through their idiosyncrasies. Furthermore the method shown allows a rapid analysis to be performed on complex composite structures in a relatively short time frame using either first principles methods or design rules.
\end{abstract}

\section{NOMENCLATURE}

\section{Introduction}

Composite materials are used within a large number of applications partly as they can be customised for their task. Furthermore, they exhibit high strength to weight ratios, excellent corrosion resistance and low maintenance costs. Conversely composite materials suffer from a relatively low modulus and therefore there is a requirement for stiffeners to be utilised within the structure. Composite structures incorporate tophat stiffeners which are excellent at providing stiffness, at the expense of weight, within the structure, an example of this approach can be seen in the top left of fig. 1 1 where the top right of the figure is the idealised representation and the bottom of the figure shows the topology of the stiffeners themselves. On top of the difficulties in stiffening the structure composite materials have a higher variability than other conventional materials and this can lead to difficulties in predicting failure in the structures.

*ajs502@soton.ac.uk 
Currently products used within real applications are developed using different rules depending on the application of the structure such as civil or marine. These rules are typically developed from first principles analysis with the addition of safety factors and/or adjustments made from experience. The adjustments made from past experiences, while ensuring safety, can also lead to structures that are overly conservative leading to a possible increase in emissions.

First principles methods allow the determination of the structural integrity of a product allowing an assessment of the structure predicted. Accurate modelling allows for a reduction in safety factors as calculations can be made rather than utilising phenomelogical factors. Analytical methods are a form of first principles approaches that can be used to model structures quickly while retaining a level of accuracy reasonable for structural assessment and most standards and rules have their origins in these approaches. They can also be used directly in design, though this is a rare occurence, by bounding them using failure criteria and can potentially reduce the weight of a product. This requires that the first principles failure criteria are both accurate but must also take into account, explicitly, all possible modes of failure for a design. A compromise between these two processes is the current trend towards the use of partial safety factors. The rapid assessment, by analytical techniques, allows easy utilisation with stochastic or simulation assessment methods resulting in reliability analysis and sensitivity factors that can be used to generate partial safety factors.

Reliability methods are used to predict the performance of structures in areas where there is a high level of variability. There are many different methods for the determination of the reliability of a product which fall into two main categories: analytical and simulation. There are three levels to the analytical reliability level1 , level-2 and level-3. Level-3 is the full probabilistic method where the model determines the link between the basic design variables affecting the response of the structure and the true nature of the failure domain. Level-2 is a semi-probabilistic method where the failure domain is idealised and is often connected with simplified probability functions of the basic design variables. An example of a Level-2 method is the First Order Reliability Methods (FORM) where a first-order Taylor series is used as approximation to the limit state. This technique can also be undertaken using a second-order Taylor expansion series, Second Order Reliability Methods (SORM). Finally the level-1 approach is a deterministic approach using either central or partial safety factors. Level-3 methods are rarely used due to the difficulty of modelling fully the entire structural and failure models and are generally used in research whereas most of the design codes available are using level-1 reliability with some codes moving towards level-2 such as the Concrete Society [1] and DNV [2]

An extensive study of literature relating to composite reliability and more specifically within the marine industry is presented in Sobey et al. [3] where the paper itself highlights the differences found between reliability analyses performed using different limits. The literature review states that whilst much work has been done in the area of composite reliability most analysis has been performed on simple structures, plates, cylindrical shells and others. An analysis of more complex structures must therefore be performed which can be compared to reliability analysis from design rules. Previous analysis has looked at the development of grillage methods for rapidly analysing the structures allowing Monte Carlo methods to be used within increasingly complex reliability assessments. Previously Blake et al. [4] had taken a step towards this by looking at a method for assessing the reliability of composite stiffened structures utilising Navier grillage theory with simple limit states. This research showed that grillage theory was good for assessing more complex composite structures however stringent limit states are required for a more realistic analysis. This previous work has shown that the choice of failure criteria is of key importance and for the analysis of first principles composite plates that more substantial failure criteria must be utilised.

This paper therefore aims to investigate the probability of failure for tophat stiffened grillages using failure criteria developed from the world wide failure exercise in comparison to popular design rules. This 
is performed using a simple grillage method for rapid assessment of complex marine structures using Monte Carlo simulations to analyse different composite materials. This model incorporates failure criteria based on strength and stiffness parameters to assess the reliability of the plates. Furthermore, a comparison of these constraints against structures developed at the minimal boundary of classification society rules is made.

\section{Structural Modelling}

\subsection{First Principles Analysis}

First principles modelling has been extended from Maneepan [5], through the addition of more stringent failure criteria and reliability analysis, to continue the development of a model that will allow investigation of lighter, more efficient craft.

To model the stiffeners within the boat hull, Navier grillage theory, found in Clarkson [6], will be used in association with elastic equivalent properties, found in Datoo [7].

The Navier grillage method is outlined next. The equation giving deflection of the stiffened plate can be seen in $\mathrm{Eq} 1$ and is a double summation dependent on the wave numbers,

$$
w(x, y)=\sum_{m=1}^{\infty} \sum_{n=1}^{\infty} a_{m n} \sin \frac{m \pi x}{L} \sin \frac{n \pi y}{B},
$$

where the value of $a_{m n}$ is a coefficient found from Eq, based on the assumption that the change in potential energy from the deflection will be a minimum, and the wave numbers, $m$ and $n$, have been kept at 11 , in the results section, as a compromise between speed and convergence. From the deflection curve of the $\mathrm{q}^{\text {th }}$ beam and $\mathrm{p}^{\text {th }}$ girder, where $\mathrm{x}$ is a constant $\mathrm{x}_{q}=q L /(b+1)$ or $\mathrm{y}_{p}=p B /(g+1)$ is a constant to investigate the deflections along the specified beam, it is possible to show the strain energy, $\mathrm{V}$ :

$$
V=\int_{0}^{L} \frac{D_{g}}{2}\left(\frac{\partial^{2} w}{\partial x^{2}}\right)_{y=y_{p}}^{2} d x+\int_{0}^{B} \frac{D_{b}}{2}\left(\frac{\partial^{2} w}{\partial y^{2}}\right)_{x=x_{q}}^{2} d y .
$$

The work done on the grillage can be shown to be:

$$
\int_{0}^{L} \int_{0}^{B} P \sum_{m=1}^{\infty} \sum_{n=1}^{\infty} a_{m n} \sin \frac{m \pi x}{L} \sin \frac{n \pi y}{B} d x d y .
$$

Minimising the potential energy $\left(\partial \mathrm{V} / \partial a_{m n}\right)$ and equating it to the work done it is then possible to find $\mathrm{a}_{m n}$,

$$
a_{m n}=\frac{16 P L B}{\pi^{6} m n\left\{m^{4}(g+1) \frac{D_{g}}{L^{3}}+n^{4}(b+1) \frac{D_{b}}{B^{3}}\right\}} .
$$

The coefficient $\mathrm{a}_{m n}$ is dependent on the flexural rigidities of the stiffeners $\left(\mathrm{D}_{g, b}\right)$. The moments can then be found in the beams or girders $\left(\mathrm{M}_{s}\right)$ from $\mathrm{Eq} 5$.

$$
M_{s}=-D_{s} \frac{\partial^{2} w}{\partial x^{2}}
$$


The shear force can also be found for the beams and girders $\mathrm{Q}_{s}$ from $\mathrm{Eq} 6$,

$$
Q_{s}=\frac{\partial M_{s}}{\partial x} .
$$

Finally, using the maximum moments and shear force in the grillage the maximum stress $\sigma_{\max }$ and shear stress $\tau_{s}$ can be determined as shown in eqs. 7 and 8 , where $\mathrm{E}_{s(i)}$ is the longitudinal modulus of elasticity of the element of a stiffener, $M_{s}$ is the moment created in the stiffener, $\mathrm{d}_{n a}$ is the vertical distance of the centroid of an element to the neutral axis, $\mathrm{D}_{s}$ is the structural rigidity of a stiffener and $\mathrm{Q}_{s}$ is the shear force in the stiffener:

$$
\begin{aligned}
& \sigma_{\text {max }}=\frac{E_{s(i)} M_{s} d_{n a}}{D_{s}}, \\
& \tau_{s}=\frac{E_{s(i)} Q_{s}}{D_{s}} \int_{0}^{s} d_{n a} d s .
\end{aligned}
$$

The tophat stiffeners are idealised as shown in fig. 1 with each stiffener being made up of 4 elements labelled 1 to 4 . Each of these elements is made up of a number of different plys.

To model the composite material within the structure, elastic equivalent properties have been used. To start with the reduced stiffness terms $\left(\mathrm{Q}_{i j}\right)$ must be found for each of the elements from the elastic properties in each ply of each element where $\mathrm{E}_{1}, \mathrm{E}_{2}, v_{12}, v_{21}$ and $\mathrm{G}_{12}$ are the properties of the material in each element, $i$, and where the 1 direction is along the fibre and 2 is orthogonal to it,

$$
Q_{11}=\frac{E_{1}}{1-v_{12} v_{21}}, \quad Q_{22}=\frac{E_{2}}{1-v_{12} v_{21}}, \quad Q_{12}=\frac{v_{21} E_{1}}{1-v_{12} v_{21}}, \quad Q_{66}=G_{12} .
$$

From these values it is then possible to calculate the transformed reduced stiffness terms, $\left(\bar{Q}_{i j}\right)$, for each ply depending on the angle of the ply specified where $\theta$ is the angle of each ply of each element [7]:

$$
\begin{aligned}
& \bar{Q}_{11}=\cos ^{4} \theta Q_{11}+\sin ^{4} \theta Q_{22}+2 \cos ^{2} \theta \sin ^{2} \theta Q_{12}+4 \cos ^{4} \theta \sin ^{2} \theta Q_{66}, \\
& \bar{Q}_{12}=\cos ^{2} \theta \sin ^{2} \theta Q_{11}+\cos ^{2} \theta \sin ^{2} \theta Q_{22}+\left(\cos ^{4} \theta+\sin ^{4} \theta\right) Q_{12}-4 \cos ^{2} \theta \sin ^{2} \theta Q_{66}, \\
& \bar{Q}_{22}=\sin ^{4} \theta Q_{11}+\cos ^{4} \theta Q_{22}+2 \cos ^{2} \theta \sin ^{2} \theta Q_{12}+4 \cos ^{4} \theta \sin ^{2} \theta Q_{66} .
\end{aligned}
$$

The laminate stiffness terms for each element can then be found by totalling the transformed reduced stiffness terms for each of the plies where $t_{k}$ is the thickness of each ply of each element:

$$
A_{i j}=\sum_{k=1}^{N} t_{k}\left(\bar{Q}_{i j}\right)_{k} .
$$

The Young's modulus for the material can then be found for each element of the stiffener:

$$
E_{i}=\frac{\left(A_{11} A_{22}-A_{12}^{2}\right)}{A_{22} t}
$$

and the second moment of area for each element of the stiffener is given by:

$$
I_{(i)}=I_{c x(i)}+a_{(i)} d_{n a(i)}^{2} .
$$


Where $\mathrm{I}_{c x(i)}$ is the moment of inertia of each element about its own neutral axis, $\mathrm{a}_{(i)}$ is the area of each element and $\mathrm{d}_{n a(i)}$ is the distance of the elements cross section to the beam or girders neutral axis.

Finally it is possible to find the flexural rigidity of the stiffener $\left(\mathrm{D}_{g}, \mathrm{D}_{b}\right)$, in either the longitudinal or transverse directions, from the following equation:

$$
D_{g}=\sum_{i=1}^{N_{g}} E_{g(i)} I_{g(i)} \quad D_{b}=\sum_{i=1}^{N_{b}} E_{b(i)} I_{b(i)}
$$

The flexural rigidity found using stress analysis can then be used to determine the stresses in the stiffeners using the Navier grillage method.

Further to previous work reported by Sobey [8] failure criteria have been added to the model to more accurately assess the behaviour of the composite materials. The failure criteria used are from the 'World Wide Failure Exercise' (WWFE) [9], [10] and [11]. The choice made for each failure type can be seen from Table 1 and was based upon the findings of Soden in the World Wide Failure Exercise [12]. The use of the three methods ensures that at least one of the proposed failure criteria for each type of failure has been used. It has been decided to always use conservative estimates leading to thicker hull designs but ensuring the safety of the vessel and allowing a fair comparison with classification society rules.

The Puck failure criteria is based upon 3-D phenomenological models where the development of the method is done through matching current theory to experimental results. The Puck method is recommended by the World Wide Failure Exercise to be used for predicting strength of unidirectional laminae and this method has been used as it gives a more conservative view for the failure of the laminates. Puck's formulation is also used for predicting the initial strength of multidirectional laminates as other methods did not predict the failure very well. Puck is further recommended to be used to predict final strength of multidirectional laminates. This criteria is shown in Table 2 .

The Zinoviev failure criteria is based on the development of maximum stress theory. This method is based on composite laminate theory and has a linear solution. Zinoviev is recommended by the World Wide Failure Exercise to predict the deformation of laminates along with a non-linear method such as Puck. This criteria is shown in Table 3

The Tsai failure criterion is developed through an interactive progressive quadratic failure criterion. This method is also based on composite laminate theory and is linear in its solution. The Tsai failure criterion are used in conjunction with Puck to determine the response of lamina. The Tsai failure criterion is the best fit to the test data reported in Soden [12] for the behaviour of the laminates. This criterion underestimates the failure stress at given points and so the Puck failure criterion can be used to check that failure does not occur. This criteria is shown in equation 17 taken from Tsai [13].

$$
\left(\frac{\sigma_{1}}{X_{T} X_{C}}\right)^{2}+\left(\frac{\sigma_{2}}{Y_{T} Y_{C}}\right)^{2}+\left(\frac{1}{X_{T}}-\frac{1}{X_{C}}\right) \sigma_{1}+\left(\frac{1}{Y_{T}}-\frac{1}{Y_{C}}\right) \sigma_{2}+\left(\frac{2 F_{1} 2 \sigma_{1} \sigma_{2}}{\sqrt{X_{T} X_{C} Y_{T} Y_{C}}}\right)+\left(\frac{\tau_{12}}{S_{12}}\right)^{2}=1
$$

The exercise concluded that in the case of buckling criteria that they 'did not address the prediction of buckling modes of failure' [12]. Buckling is a key part of failure in hull stiffeners and therefore an Euler based rule, seen in equation 18 , where the crown and web are assumed to be taken as clamped at both ends has been used to constrain the model for both the crown and the webs and is taken from [14],

$$
\sigma_{c r i, w e b}=\frac{6.97 \pi^{2} E_{s}}{12\left(1-v_{12}^{2}\left(d_{s} / c_{s}\right)^{2}\right)}, \quad \sigma_{c r i, \text { crown }}=\frac{6.97 \pi^{2} E_{s}}{12\left(1-v_{12}^{2}\left(a_{s} / b_{s}\right)^{2}\right)} .
$$

Furthermore an arbitrary deflection criteria of $10 \%$ of the length has been included to ensure that materials with a low stiffness and cost cannot be selected without creating a thicker topology. 


\subsection{Design Rules}

Design rules are the main rules for structural design of hulls used within the boatbuilding community. These rules are based upon first principles and have been developed from years of experience.

\section{Lloyd's Register}

Lloyd's Register Rules for Special Service Craft is a classification society rule developed for craft over $24 \mathrm{~m}$ in length but sometimes utilised in craft under. The rules have a specific set for development of composite structures which allows new materials to be used once the required mechanical properties have been found from experiment. The rules are developed from first principles but with changes made to increase safety, based on the use of these rules over time. The composite rules are originally based on those developed from boats constructed from steel.

Determining the adequacy of structures is based on defining the boat characteristics and the environment under which it is expected to operate. A pressure, under which the hull is likely to be subjected, can then be determined, dependent upon the position of the panel within the hull form. The panel thickness is then defined using this pressure and the distance separating the stiffeners. The stiffener geometry is determined from minimum thickness criteria and determination of the stresses and deflections calculated. These can be compared to stress and deflection limits dependent upon the position of the panel.

\section{ISO 12215-5}

ISO $12215-5$ is a newer standard for scantling determination developed for recreational craft under $24 \mathrm{~m}$. These rules also have a specific section for composite materials allowing determination of materials through testing. The rules were developed to reduce the scantling size of smaller recreational craft and to be easily used by structural designers.

The route for assessing structures using ISO 12215-5 is similar to that for Lloyd's Register Rules. The pressure is determined from the conditions and the characteristics of the boat and the panel thickness is determined from the pressure, the stiffener spacing, and the expected stress. The stiffeners are determined through assessing the stresses found to ensure that they do not fail but are further constrained by ratio limits between sections of the stiffeners, a minimum web area and section modulus.

\section{The Reliability Approach}

\subsection{Monte Carlo Methods}

A Monte Carlo simulation has been chosen for the prediction of the reliability of composites. This technique allows changes to easily be incorporated into the model and to allow systems reliability and covariance to be added in future models. The Monte Carlo method has three main steps:

1. generate a randomly distributed set of input variables,

2. perform structural calculations for each input set,

3. determine probability of failure from a large number of repetitions.

A number of simulations were run for each set of statistical distributions resulting in a given reliability for that product and the production technique used. For each of these simulations the values of the input variables must be determined. The first step is to generate a uniform distribution that can then be mapped using 
the quantile function to the distribution function, in this case found using "Numerical Recipes" [15]. This function then generates a number of values for each variable and these are mapped to different distributions which represent the manner in which the variable is encountered.

Different inputs are generally grouped together with statistical distributions as determined by structural codes e.g. CIRIA [16], DNV [2] or EUROCOMP [1]. Pressure and material definitions are typically of a Weibull and Normal nature respectively, as can be seen from Table 4 given by the DNV design rules [2].

Having determined the statistical input variables for each simulation it is then possible to determine the outputs. In this case outputs are deflection, failure criteria conformity, and maximum stress from the model being used i.e. the grillage and to generate the equations for the limit states Eq. 19 and Eq. 20.

$$
\begin{aligned}
x_{\text {stress }}= & X_{t}\left(E_{f}, E_{m}, V_{f}, \epsilon_{f}^{*}\right) \\
& -\sigma_{\max }\left(L, B, P, E_{f}, E_{m}, G_{F}, G_{m}, V_{f}\right) \\
x_{\text {deflection }}= & k \times w_{\max } \\
& -w\left(L, B, P, E_{f}, E_{m}, G_{F}, G_{m}, V_{f}\right) \\
\sigma_{\text {failure }}= & C r i t_{\text {Fail }}\left(E_{f}, E_{r}, V_{f}, \epsilon_{f}^{*}, \epsilon_{r}^{*}\right) \\
& -\left(\sigma_{\text {max }}\left(L, B, P, E_{f}, E_{r}, G_{F}, G_{r}, V_{f}\right)+\tau\left(L, B, P, E_{f}, E_{r}, G_{F}, G_{r}, V_{f}\right)\right. \\
& +w\left(L, B, P, E_{f}, E_{r}, G_{F}, G_{r}, V_{f}\right)
\end{aligned}
$$

$\sigma_{\text {failure }}$ is the limit state for the failure criteria summarised in section 2.1 it is made up of the deflection, stress and strain in comparison to the failure criteria generated from the material properties of the composite structure.

It will then be possible to determine the reliability of the panel and the sensitivity of the structure to each input variable, determined from an index defined in Rubinstein [17]:

$$
\widehat{\nabla^{(k)}} \ell(\mathbf{u})=\frac{1}{N} \sum_{i=1}^{N} H\left(\mathbf{X}_{i}\right) \mathcal{S}^{(k)}\left(\mathbf{u} ; \mathbf{X}_{i}\right)
$$

where $\widehat{\nabla^{(k)}} \ell(\mathbf{u})$ is the gradient of the response, $H\left(\mathbf{X}_{i}\right)$ is the sample performance and $\mathcal{S}^{(k)}\left(\mathbf{u} ; \mathbf{X}_{i}\right)$ is the score function. The gradient can be found from the score functions of each distribution defined in Rubinstein [17] and shown in eq. 23, for the Normal distribution, and in eq. 24, for the Weibull distribution,

$$
\begin{aligned}
& \mathcal{S}(\mathbf{u} ; x)=\left(\sigma^{-2}(x-\mu),-\sigma^{-1}+\sigma^{-3}(x-\mu)^{2}\right), \\
& \mathcal{S}(\mathbf{u} ; x)=\left(\alpha-1+\ln (\beta x)\left[1-(\beta x)^{\alpha}\right], \frac{\alpha}{\beta}\left[1-(\beta x)^{\alpha}\right]\right) .
\end{aligned}
$$

These sensitivity values relate the effect that the input characteristics have upon the output and are the gradients; the larger the value the higher the effect the input has on the output reliability index. 


\section{Plate Reliability Analysis}

\subsection{Verification}

Verification of the Monte Carlo simulation was determined by comparison with work previously carried out on a composite grillage plate. To determine the reliability of the plate it is assumed to have characteristics as shown in Table 5 these properties have been taken from Blake et al. [4].

Where normal distributions have been shown they represent a truncated normal distribution to ensure that negative results could not be introduced. A convergence analysis was performed shown in Table 6 and for which the convergence can be seen to be occuring in fig. 2 .

These results were then compared to the reliability generated from FORM/SORM on the same structure published by Blake et al. [4] the results of which are replicated in Table 7

From these results it can be seen that a good degree of accuracy was reached and when compared against the Monte Carlo simulation the FORM results had an error of 5.5\% in probability of failure. This compared to the SORM results the Monte Carlo simulation produced results $42.5 \%$ of the probability of failure showing the method verified for the analysis of the structurally optimised plate.

\subsection{Plate Analysis}

Probabilities of failure have been investigated, for the optimised plates given in Sobey et al. [18], to determine the reliability of the structures that have been designed. Furthermore, sensitivity analysis has been carried out to determine the manner in which the different properties affect the structural design. The stiffened plates have properties of geometric variation as outlined in Table 8 and for comparison use the same coefficients of variation as that of the earlier study by Blake et al. [4].

\subsubsection{First Principles}

The reliability for the first principles model has been carried out using the stiffener topology given in Table 9.

The plate topology is given in Table 10

This topology has been used to determine a structural reliability determining how often it is expected that a plate breaks the limit state. The reliability has been used to investigate the sensitivity of the outputs, the stress, strength and deflection, to the input characteristics. The sensitivity values have been normalised by multiplying the mean of the characteristic and have been represented as a percentile to give an easy understanding of the effect these characteristics have on the reliability.

The structural reliability for the first principles model resulted in a probability of failure of $6 \times 10^{-6}$ which indicates a level of reliability that is below that required by the DNV rules. The sensitivity analysis is shown in fig. 3 with the four largest values shown in contrast to the other variables. The results of the sensitivity analysis show where changes in cost can be made so as to ensure that the structural reliability stays at a high level. For example these results show that longitudinal web height was the most important factor for the structural engineer and therefore may be an area the production engineer may particularly want to focus on. The other parts of the plate are less sensitive and therefore may require less focus saving time and cost without large variation in the structural integrity. The panel shows a high importance for the geometrical properties such as the width and length of the panel indicating the stiffener spacing and web height were some of the main factors in increasing the stiffness. This was especially the case longitudinally as in this direction there were bigger stiffeners where small changes had larger effects. Furthermore, the failure of the 
panel was highly sensitive to the volume fraction as small changes here can make large differences to the makeup of the material.

\subsubsection{Lloyds Register}

The reliability of the Lloyds Register Rules plate has also been determined. The stiffener topology is shown in Table 11. The plate topology is shown in Tables 12 The Lloyds Register Rules plate has a probability of failure of $2.33 \times 10^{-5}$ and again exhibited a probability of failure deemed safe in the DNV rules. The sensitivity analysis from this calculation results in the percentage sensitivities shown in fig. 4 The structural reliability of the Lloyds plate is most affected by the longitudinal web height and the stiffeners are proportionally similar to the first principles panel which are similar but smaller. As this is the case the web height effects the deflection of the plate, the major failure mode, in a similar manner. This again indicates that this might be an area of focus for the production engineers. The Lloyds register panel had similar sensitivities to the first principles panel with the longitudinal and transverse web heights and plate length and width being the most important properties. The number of stiffeners in the longitudinal Lloyds register panel is larger and due to this the transverse stiffener web height becomes more important to the failure of the panel.

\subsubsection{ISO 12215-5}

The reliability of the ISO 12215-5 plate has also been determined from a topology given in Table 13 . The plate has a topology as shown in Table 14

The structural reliability for the ISO 12215-5 plate has a probability of failure of $2.61 \times 10^{-6}$ and has a sensitivity as shown in fig. 5. The ISO $12215-5$ plate is more structurally sensitive to the volume of fibres in the plate than the other panels and shows a different sensitivity profile to the panels generated with the other rules. Once again the plates failed in deflection rather than under stress showing that the plate had a high reliability. However, due to the difference in the stiffeners it appears that this failure was driven by a different variable. The ISO $12215-5$ panel is different in sensitivity to the other two panels. However, this may be due to the difference in topology where this panel had a larger number of smaller stiffeners across the design. The volume fraction became the most important as changes in the material properties were seen across the whole panel. Crown height also played a larger role in the sensitivity of this design as did the pressure.

\section{Summary}

A methodology for structural reliability has been developed and validated against previous work. This method has been used to make assessments of different structural models. The probability of failure for each panel has been collated into Table 15 .

There are no strength failures so it can be seen that all of the rules performed adequately. The most reliable plate was that created from the first principles panel the next was for the plate and finally the least reliable was that found using Lloyds Register. The probabilities for each panel are similar to each other and the Lloyds Register Rules plate was the marginally the least reliable however, it would be expected to be the most reliable due to the safety factors used within the creation of these rules. The ISO standard would be expected to be the next most reliable plate as it uses partial safety factors, gaining a reduction in mass. Finally the first principles approach would be expected to be the least reliable as it uses multiple failure criteria to create a minimal safety factor, even for a strength assessment. It is likely that the first principles rules performed well in a simple one directionally loaded scenario as the failure criteria and modelling for 
these states are well understood. Further analysis will be required under multiple loading directions as there are a number of effects that rules take into account of through phenomenological means that will not be accounted for using the first principles approach. Whilst these approaches lead to a safer plate they are not geared towards the loading scenario examined in this analysis.

The results also show that in this scenario the designs do not produce a stress failure. This meant that all of the failures were for the serviceability state, deflection. This may have been down to the arbitrary figure used in this regard. However, these panels have only been loaded in one plane and it is the combination of these more complex loading scenarios that can cause failures. The criterion applied was one chosen at random to replicate the service limit state and it is an important consideration for composite materials that must be taken into account due to the low stiffness exhibited. Whilst the composite materials may be designed in a manner to counteract the stress in a plate the change in deflection might be more of a concern than in traditional materials.

The sensitivity results show a different dependency of the failure from the dimensions of the plate. General statements therefore, cannot be made about which part should be changed for any given design and that it is of key importance that this analysis must be performed for each individual design. It is interesting to note the similarities between the Lloyds Register Rules and first principles plates in in terms of the sensitivity in comparison to the ISO standard. Furthermore, as shown by Sobey et al. [19], the input distributions can have a large impact upon the final output probability of failure of the model. It is therefore of key importance that for use of these reliability techniques that the input distributions are modelled accurately from experimental data found from real applications. Finally the method shown can be seen to provide a rapid analysis for composite structures working well with design rules and first principles methods.

\section{Conclusions}

Reliability analysis, using a simple grillage method, has been shown as an effective tool for design. The ability to utilise this method, instead of computationally expensive FEA, allows a swift approximation for the reliability of composite boat structures. Investigation into the reliability of the design rules against those of a first principles method show that the panels had a similar probability of failure with the first principles panel performing marginally better than those with the design rules. Investigations into the first principles method shows that it will be important to include other factors than first ply strength to investigate the failure of the plates and that deflection was the main mode of failure in this example.

\section{References}

[1] Report of a Concrete Society Committee. Design guidance for strengthening concrete structures using fibre composite materials. Technical Report No. 55, The Concrete Society, 2004.

[2] DNV. Design of offshore steel structures load and resistance factor design method. Technical Report OSC101, Oslo, 2000.

[3] A.J SOBEY, J.I.R. BLAKE, and SHENOI.R.A. Monte carlo reliability analysis of tophat stiffened composite plate structures under out of plane loading. Reliability Engineering and System Safety, vol. 110:41-49, 2013.

[4] J.I.R. BLAKE, R.A. SHENOI, O. DAS, and N. YANG. The application of reliability methods in 
the design of stiffened frp composite panels for marine vessels. Ship and Offshore Structures, vol. 4(2):pp.287-297, 2009.

[5] K. MANEEPAN. Genetic Algorithm based Optimisation of FRP Composite Plates in Ship Structures. $\mathrm{PhD}$ thesis, University of Southampton, 2007.

[6] J. CLARKSON. The elastic analysis of flat grillages. Cambridge University Press, 1965.

[7] M.H. DATOO. Mechanics of Fibrous Composites. Elsevier Science Publishers Ltd., Essex, England, 1991.

[8] A.J. SOBEY, J.I.R. BLAKE, and R.A. SHENOI. Optimization of composite boat hull structures. In Computer and Information Management Applications for Shipbuilding (COMPIT),Liege, pages pp.502-515, 2008.

[9] A.S. KADDOUR, M.J. HINTON, and P.D. SODEN. A comparison of the predictive capabilities of current failure theories for composite laminates: additional contributions. Composites Science and Technology, vol. 64:pp.449-476, 2004.

[10] M.J. HINTON, A.S. KADDOUR, and P.D. SODEN. Evaluation of failure prediction in composite laminates: background to 'part b' of the exercise. Composites Science and Technology, vol. 62:pp.14811488, 2002.

[11] M.J. HINTON, A.S. KADDOUR, and P.D. SODEN. Evaluation of failure prediction in composite laminates: background to 'part c' of the exercise. Composites Science and Technology, vol. 64:pp.321$327,2004$.

[12] P.D. SODEN, A.S. KADDOUR, and M.J. HINTON. Recommendations for designers and researchers resulting from the world-wide failure exercise. Composites Science and Technology, vol. 64:pp.589604, 2004.

[13] A. KURAISHI, S.W. TSAI, and K.K.S. LIU. A progressive quadratic failure criterion, part b. Composites Science and Technology, vol. 62:pp.1683-1695, 2002.

[14] M.L. GAMBHIR. Stability analysis and design of structures. Springer, 2004.

[15] W.H. PRESS. Numerical Recipes. Cambridge University Press, 1986.

[16] J.M.C. CADAI, T.J. STRATFORD, L.C. HOLLAWAY, and W.G. DUCKETT. Strengthening metallic structures using externally bonded fibre-reinforced polymers. Classic House, 2004.

[17] R.Y. RUBINSTEIN and D.P. KROESE. Simulation and the Monte Carlo Method. Wiley, 2008.

[18] A.J. SOBEY, J.I.R. BLAKE, and R.A. SHENOI. Optimisation of composite boat hulls using first principles and design rules. Ocean Engineering, vol. 65:62-70, 2013.

[19] A.J. SOBEY, J.I.R. BLAKE, and R.A. SHENOI. Stochastic methods used in design optimisation of composite boat hull topologies. In Light Weight Marine Structures (LIWEM), Glasgow, 2009.

[20] A. PUCK and H. SCHURMANN. Failure analysis of frp laminates by means of physically based phenomenological models. Composites Science and Technology, vol. 58:pp.1045-1067, 1998. 
[21] A. PUCK and H. SCHURMANN. Failure analysis of frp laminates by means of physically based phenomenological models. Composites Science and Technology, vol. 62:pp.1633-1662, 2002.

[22] K. LIU and S.W. TSAI. A progressive quadratic failure criterion for a laminate. Composites Science and Technology, vol. 58:pp.1023-1032, 1998.

[23] P.A. ZINOVIEV, S.V. GRIGORVIEV, O.V. LEBEDEVAB, and L.P. TAIROVA. The strength of multilayered composites under a plane-stress state. Composites Science and Technology, vol. 58, 1998.

[24] P.A. ZINOVIEV, O.V. LEBEDEVA, and L.P. TAIROVA. A coupled analysis of experimental and theoretical results on the deformation and failure of composite laminates under a state of plane stress. Composites Science and Technology, vol. 62:pp.1711-1723, 2002.

[25] R.A. SHENOI, P. DAS, A.K. NAYAK, and J.I.R. BLAKE. Safe design of a composite structure - a stochastic approach. Technical report, University of Southampton University of Glasgow and Strathclyde, 2006. 


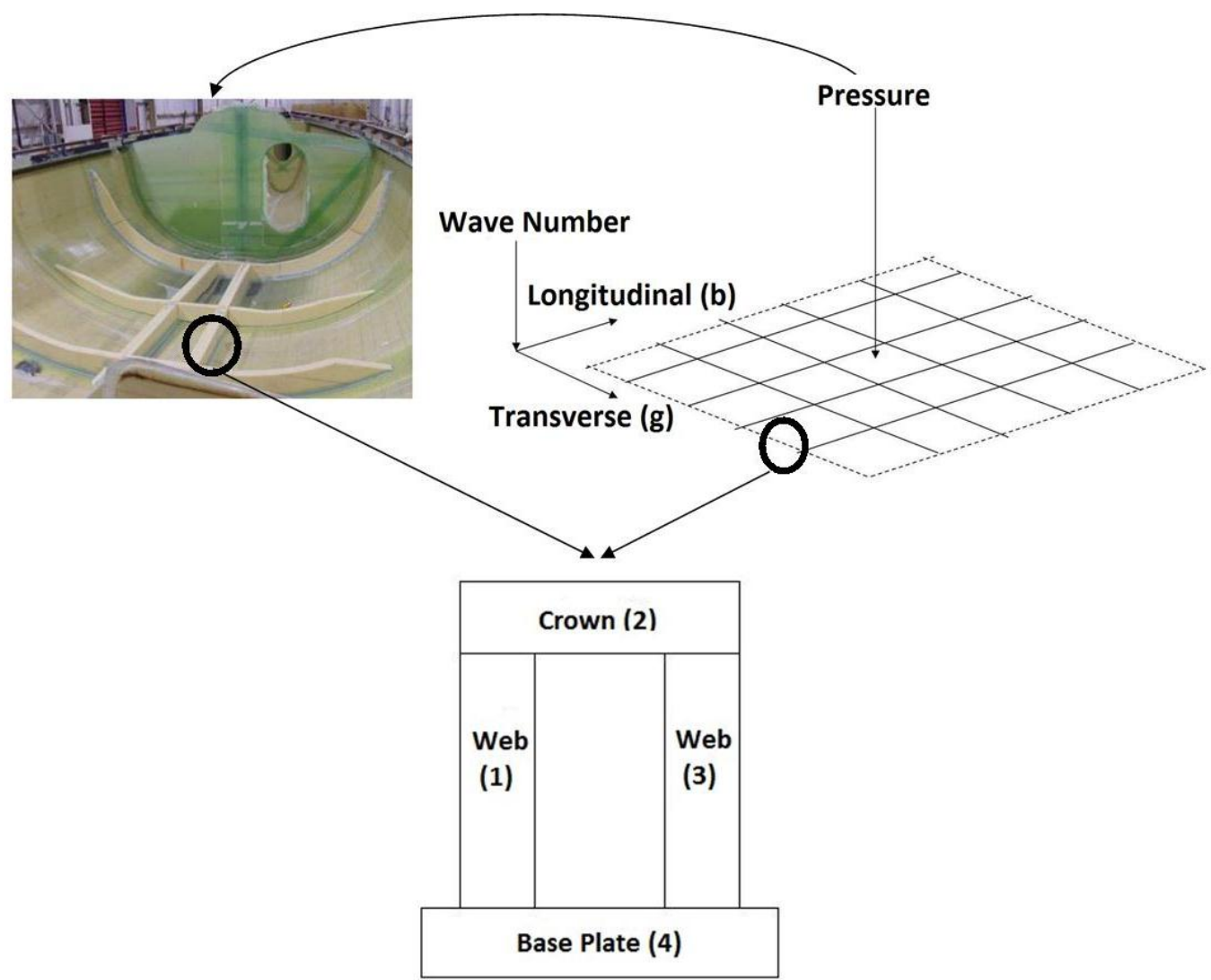

Figure 1: Grillage Stiffened Boat Hull 


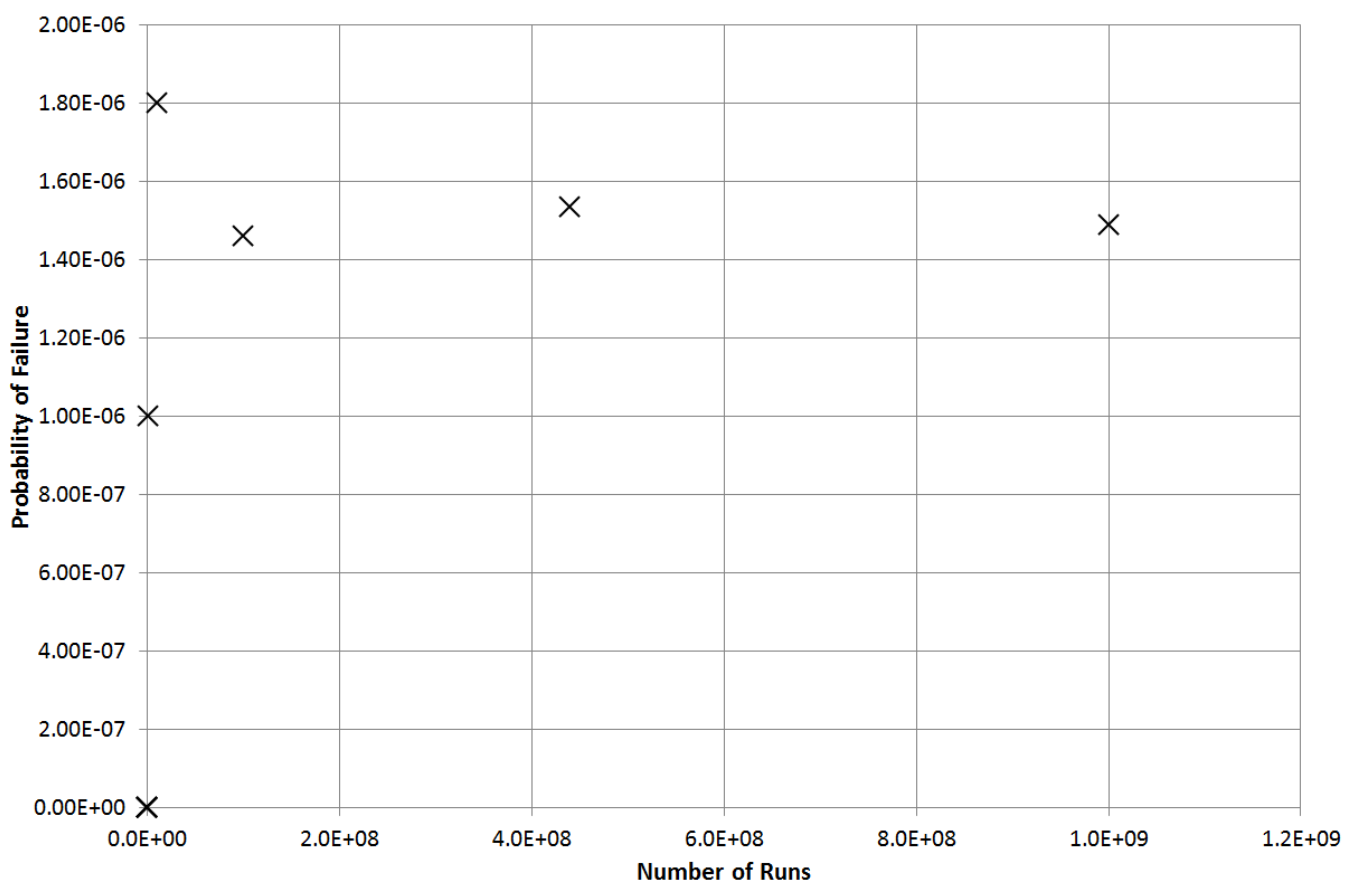

Figure 2: Convergence of Monte Carlo Simulation 


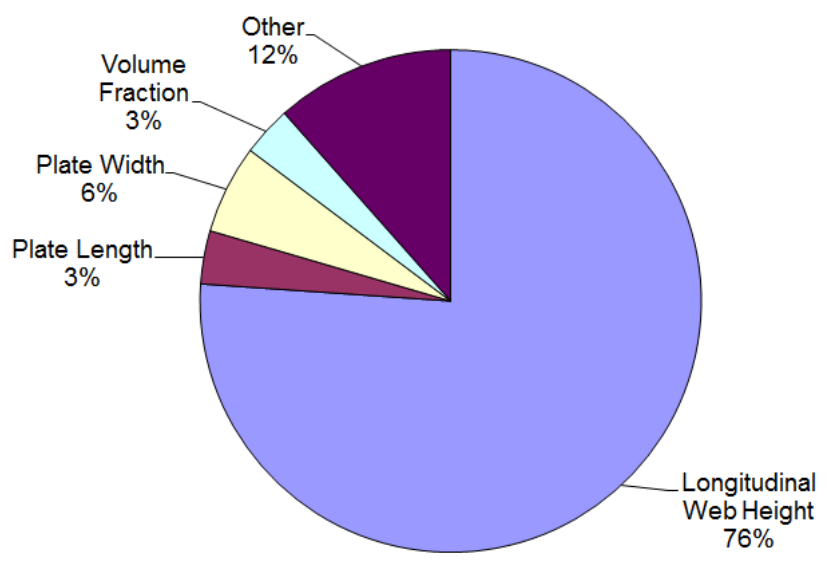

Figure 3: First principles structural sensitivity 


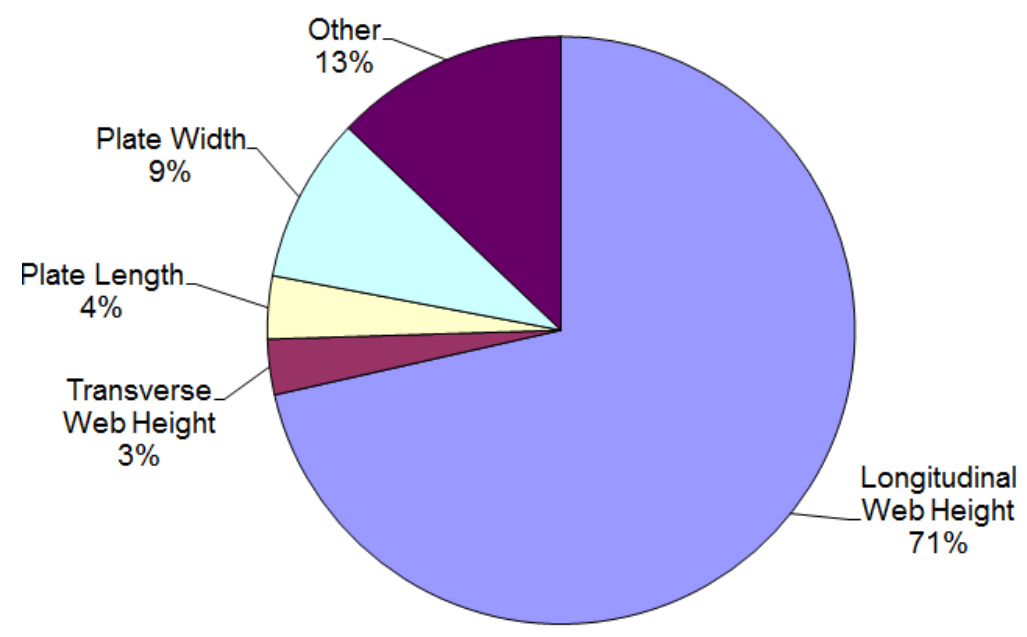

Figure 4: Lloyds register structural sensitivity 


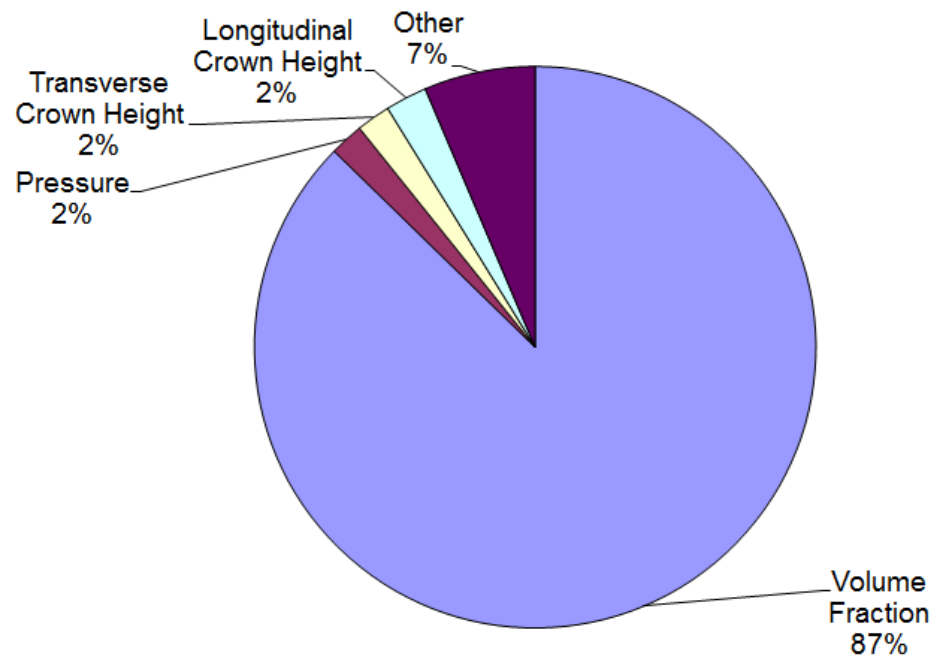

Figure 5: ISO 12215-5 structural sensitivity 


\begin{tabular}{|c|c|}
\hline$a, b=$ & Stiffener spacing \\
\hline $\mathrm{a}_{s}=$ & Crown width \\
\hline$a_{m n}=$ & Coefficient for grillage analysis \\
\hline $\mathrm{b}_{s}=$ & Crown thickness \\
\hline$b, g=$ & Numbers of beams and girders \\
\hline $\mathrm{c}_{s}=$ & Web width \\
\hline $\mathrm{D}_{s x, s y}=$ & Stiffener rigidities \\
\hline $\mathrm{d}_{n a}=$ & Neutral axis of the stiffeners \\
\hline $\mathrm{d}_{s}=$ & Web height \\
\hline $\mathrm{E}=$ & Young's modulus \\
\hline $\mathrm{E}_{f 1}=$ & Young's modulus of fibre \\
\hline $\mathrm{G}_{f, r}=$ & Shear modulus of fibres and resin \\
\hline$I=$ & Second moment of area \\
\hline $\mathrm{I}_{c x}=$ & Moment of inertia \\
\hline $\mathrm{L}, \mathrm{B}=$ & Length and breadth of plate \\
\hline $\mathbf{M}_{s}=$ & Moments of stiffeners \\
\hline $\mathrm{m}, \mathrm{n}=$ & Wave numbers \\
\hline $\mathrm{m}_{\sigma f}=$ & Mean stress magnification factor \\
\hline $\mathrm{n}_{b, g}=$ & Number of beams or girders \\
\hline $\mathrm{P}=$ & Pressure \\
\hline $\mathrm{P}_{f}=$ & Probability of failure \\
\hline $\mathrm{Q}_{i j}=$ & Elasticity tensors \\
\hline $\mathrm{Q}_{s}=$ & Shear force of stiffeners \\
\hline $\bar{Q}=$ & Reduced stiffness terms \\
\hline$t=$ & Ply thickness \\
\hline $\mathrm{V}_{f}=$ & Volume Fraction \\
\hline $\mathrm{X}_{T}=$ & Tens. strength parallel to fibres \\
\hline $\mathrm{w}=$ & Deflection \\
\hline$\alpha=$ & Sensitivity factor \\
\hline$\epsilon_{f, r}^{*}=$ & Stiffness of fibre and resin \\
\hline$\mu=$ & Mean \\
\hline$\sigma_{c r i}=$ & Critical Stress \\
\hline$\sigma_{1 D}=$ & Stress value for linear degradation \\
\hline$v=$ & Poisson's ratio \\
\hline$\Phi=$ & Cumulative function of the standard normal distribution \\
\hline$H\left(\mathbf{X}_{i}\right)=$ & Sample performance \\
\hline$\sigma=$ & Stress \\
\hline$\widehat{\nabla^{(k)} \ell}=$ & Gradient of the response \\
\hline $\mathcal{S}^{(k)}\left(\mathbf{u} ; \mathbf{X}_{i}\right)=$ & Score function \\
\hline$\tau=$ & Shear stress \\
\hline
\end{tabular}


Table 1: Failure Criteria

\begin{tabular}{|l|c|}
\hline Failure Type & Criteria \\
\hline $\begin{array}{l}\text { Predicting the } \\
\text { response of lamina }\end{array}$ & Puck [20], [21] and Tsai [22], [13] \\
\hline $\begin{array}{l}\text { Predicting final strength } \\
\text { of multidirectional laminates }\end{array}$ & Puck [20], [21] \\
\hline $\begin{array}{l}\text { Predicting the } \\
\text { deformation of laminates }\end{array}$ & Zinoviev [23], [24] and Puck [20], [21] \\
\hline
\end{tabular}


Table 2: Puck failure criteria [21]

\begin{tabular}{|l|c|}
\hline Fibre failure in tension & \multicolumn{2}{|c|}{$\frac{1}{\epsilon_{1 T}}\left(\epsilon_{1}+\frac{v_{f 12}}{E_{f 1}} m_{\sigma f} \sigma_{2}\right)=1$} \\
\hline Fibre failure in compression & $\frac{1}{\epsilon_{1 C}}\left|\left(\epsilon_{1}+\frac{v_{f 12}}{E_{f 1}} m_{\sigma f} \sigma_{2}\right)\right|=1-\left(10 \gamma_{21}\right)^{2}$ \\
\hline $\begin{array}{l}\text { Inter-fibre failure mode A } \\
\text { for transverse tension) }\end{array}$ & $\sqrt{\left(\frac{\tau_{12}}{S_{12}}\right)^{2}+\left(\rho_{\perp \|}^{(+)} \frac{Y_{T}}{S_{21}}\right)^{2}+\left(\frac{\sigma_{2}}{Y_{T}}\right)^{2}+\rho_{\perp \|}^{(+)} \frac{\sigma_{2}}{S_{12}}=1-\frac{\sigma_{1}}{\sigma_{1 D}}}$ \\
\hline $\begin{array}{l}\text { Inter-fibre failure mode B } \\
\text { (for moderate transverse compression) }\end{array}$ & $\frac{1}{S_{21}}\left(\sqrt{\tau_{21}^{2}+\left(\rho_{\perp \|}^{(-)} \sigma_{2}\right)^{2}}\right)+\rho_{\perp \|}^{(-)} \sigma_{2}=1-\frac{\sigma_{1}}{\sigma_{1 D}}$ \\
\hline $\begin{array}{l}\text { Inter-fibre failure mode C } \\
\text { (for large transverse tension) }\end{array}$ & $\left.\left[\frac{\tau_{21}}{2\left(1+\rho_{\perp \perp}^{(-)}\right) S_{21}}\right)^{2}+\left(\frac{\sigma_{2}}{Y_{C}}\right)^{2}\right] \frac{Y_{C}}{\left(-\sigma_{2}\right)}=1-\frac{\sigma_{1}}{\sigma_{1 D}}$ \\
\hline
\end{tabular}


Table 3: Zinoviev failure criteria [24]

\begin{tabular}{|l|c|}
\hline Longitudinal tension failure & $\sigma_{1}=X_{T}$ \\
\hline Longitudinal compressive failure & $\sigma_{1}=X_{C}$ \\
\hline Transverse tensile failure & $\sigma_{2}=Y_{T}$ \\
\hline Transverse compressive failure & $\sigma_{2}=X_{C}$ \\
\hline In-plane shear failure & $\tau_{12}=S_{12}$ \\
\hline
\end{tabular}


Table 4: Typical Distributions for Input Variables DNV [2]

\begin{tabular}{cc}
\hline Variable & Distribution Type \\
\hline Current - Long Term Speed (Pressure) & Weibull \\
Properties - Yield Strength (Steel) & Normal \\
Properties - Young's Modulus & Normal \\
Properties - Initial Deformation of Panels & Normal \\
\hline
\end{tabular}


Table 5: Panel Characteristics - Verification Blake et al. [4]

\begin{tabular}{|c|c|c|c|c|c|}
\hline & \multicolumn{2}{|c|}{ carbon/epoxy } & \multicolumn{2}{|c|}{ e-glass/vinylester } & \\
\hline Material & Mean & $\mathrm{CoV} \%$ & Mean & CoV \% & Distribution \\
\hline Length & $3810 \mathrm{~mm}$ & 3 & $3810 \mathrm{~mm}$ & 3 & Normal \\
\hline Breadth & $3810 \mathrm{~mm}$ & 3 & $3810 \mathrm{~mm}$ & 3 & Normal \\
\hline Pressure & $137 \mathrm{kPa}$ & 15 & $137 \mathrm{kPa}$ & 15 & Weibull \\
\hline$E_{f}$ & $826 \mathrm{GPa}$ & 5 & $71 \mathrm{GPa}$ & 3 & Normal \\
\hline$E_{m}$ & $3 \mathrm{GPa}$ & 3 & 3.4GPa & 3 & Normal \\
\hline$G_{f}$ & $41.3 \mathrm{GPa}$ & 3 & $35.5 \mathrm{GPa}$ & 3 & Normal \\
\hline$G_{m}$ & $1.09 \mathrm{GPa}$ & 3 & $1.13 \mathrm{GPa}$ & 3 & Normal \\
\hline$V_{f}$ & 0.6 & 3 & 0.55 & 3 & Normal \\
\hline$\epsilon_{f}^{*}$ & 0.3 & 3 & 3 & 3 & Normal \\
\hline
\end{tabular}


Table 6: Verification of Monte Carlo Simulation

\begin{tabular}{ccc}
\hline Runs & Failures & Probability of Failure \\
\hline $10^{1}$ & 0 & 0 \\
$10^{2}$ & 0 & 0 \\
$10^{3}$ & 0 & 0 \\
$10^{4}$ & 0 & 0 \\
$10^{5}$ & 0 & 0 \\
$10^{6}$ & 1 & $1 \times 10^{-6}$ \\
$10^{7}$ & 18 & $1.8 \times 10^{-6}$ \\
$10^{8}$ & 146 & $1.46 \times 10^{-6}$ \\
$4.44 \times 10^{8}$ & 675 & $1.53 \times 10^{-6}$ \\
$10^{9}$ & 1490 & $1.49 \times 10^{-6}$ \\
\hline
\end{tabular}


Table 7: Comparison of FORM/SORM and Monte Carlo Reliability

\begin{tabular}{ccc}
\hline Method & $\begin{array}{c}\text { Probability of Failure } \\
P_{f}\left(10^{-6}\right)\end{array}$ & \% Error compared to SORM \\
\hline FORM [25] & 1.384 & $32.4 \%$ \\
SORM [25] & 1.045 & $0 \%$ \\
Monte Carlo & 1.49 & $42.5 \%$ \\
\hline
\end{tabular}


Table 8: Panel Properties

\begin{tabular}{cccc}
\hline Material & Mean & Coefficient of Variance(\%) & Distribution \\
\hline Length & $24000 \mathrm{~mm}$ & 3 & Normal \\
Breadth & $2000 \mathrm{~mm}$ & 3 & Normal \\
Pressure & $131 \mathrm{kPa}$ & 15 & Weibull \\
$E_{f}$ & $71 \mathrm{GPa}$ & 5 & Normal \\
$E_{m}$ & $3 \mathrm{GPa}$ & 3 & Normal \\
$G_{f}$ & $35.5 \mathrm{GPa}$ & 3 & Normal \\
$G_{m}$ & $1.09 \mathrm{GPa}$ & 3 & Normal \\
$V_{f}$ & 0.55 & 3 & Normal \\
$\epsilon_{f}^{*}$ & 0.03 & 3 & Normal \\
Crown Width & Rule Specific & 3 & Normal \\
Crown Height & Rule Specific & 1 & Normal \\
Web Width & Rule Specific & 1 & Normal \\
Wed Height & Rule Specific & 3 & \\
\hline
\end{tabular}


Table 9: Stiffener Topology for reliability comparison - First Principles

\begin{tabular}{ccccc}
\hline Stiffener Type & $\begin{array}{c}\text { Web } \\
\text { Height }\end{array}$ & $\begin{array}{c}\text { Web } \\
\text { Thickness }\end{array}$ & $\begin{array}{c}\text { Crown } \\
\text { Width }\end{array}$ & $\begin{array}{c}\text { Crown } \\
\text { Thickness }\end{array}$ \\
\hline Longitudinal & $84.1 \mathrm{~mm}$ & $3.5 \mathrm{~mm}$ & $101.1 \mathrm{~mm}$ & $5.32 \mathrm{~mm}$ \\
Transverse & $46.1 \mathrm{~mm}$ & $1.26 \mathrm{~mm}$ & $101.1 \mathrm{~mm}$ & $9.16 \mathrm{~mm}$ \\
\hline
\end{tabular}


Table 10: Plate Topology for reliability comparison - First Principles

Longitudinal Transverse Plate

Stiffener Spacing Stiffener Spacing Thickness

\begin{tabular}{llll}
\hline Plate Topology & $2200 \mathrm{~mm}$ & $720 \mathrm{~mm}$ & $3.3 \mathrm{~mm}$ \\
\hline
\end{tabular}


Table 11: Stiffener Topology for reliability comparison - Lloyd's Register

\begin{tabular}{ccccc}
\hline Stiffener Type & $\begin{array}{c}\text { Web } \\
\text { Height }\end{array}$ & $\begin{array}{c}\text { Web } \\
\text { Thickness }\end{array}$ & $\begin{array}{c}\text { Crown } \\
\text { Width }\end{array}$ & $\begin{array}{c}\text { Crown } \\
\text { Thickness }\end{array}$ \\
\hline Longitudinal & $19.45 \mathrm{~mm}$ & $2.6 \mathrm{~mm}$ & $42.5 \mathrm{~mm}$ & $2.6 \mathrm{~mm}$ \\
Transverse & $82 \mathrm{~mm}$ & $6 \mathrm{~mm}$ & $44.5 \mathrm{~mm}$ & $6 \mathrm{~mm}$ \\
\hline
\end{tabular}


Table 12: Plate Topology for reliability comparison - Lloyd's Register

Longitudinal Transverse Plate

Stiffener Spacing Stiffener Spacing Thickness

\begin{tabular}{llll}
\hline Plate Topology & $212 \mathrm{~mm}$ & $222 \mathrm{~mm}$ & $5.4 \mathrm{~mm}$ \\
\hline
\end{tabular}


Table 13: Stiffener Topology for reliability comparison - ISO 12215-5

\begin{tabular}{ccccc}
\hline Stiffener Type & $\begin{array}{c}\text { Web } \\
\text { Height }\end{array}$ & $\begin{array}{c}\text { Web } \\
\text { Thickness }\end{array}$ & $\begin{array}{c}\text { Crown } \\
\text { Width }\end{array}$ & $\begin{array}{c}\text { Crown } \\
\text { Thickness }\end{array}$ \\
\hline Longitudinal & $10 \mathrm{~mm}$ & $1.17 \mathrm{~mm}$ & $1 \mathrm{~mm}$ & $4.39 \mathrm{~mm}$ \\
Transverse & $161 \mathrm{~mm}$ & $5.66 \mathrm{~mm}$ & $4 \mathrm{~mm}$ & $4.03 \mathrm{~mm}$ \\
\hline
\end{tabular}


Table 14: Plate Topology for reliability comparison - ISO 12215-5

Longitudinal Transverse Plate

Stiffener Spacing Stiffener Spacing Thickness

\begin{tabular}{llll}
\hline Plate Topology & $386 \mathrm{~mm}$ & $232 \mathrm{~mm}$ & $10.6 \mathrm{~mm}$
\end{tabular}


Table 15: Comparison of Lloyds Register Rules for Special Service Craft and First Principles Probabilities of Failure

\begin{tabular}{cccc}
\hline Method & $\begin{array}{c}\text { Safety } \\
\text { Factor }\end{array}$ & $\begin{array}{c}\text { Reliability } \\
\text { Index, } \beta\end{array}$ & $\begin{array}{c}\text { Probability of } \\
\text { Failure, } P_{f}\end{array}$ \\
\hline $\begin{array}{c}\text { Lloyds Register Rules for } \\
\text { Special Service Craft }\end{array}$ & 3 & 4.18 & $2.33 \times 10^{-5}$ \\
First Principles Method & Minimal & 4.48 & $6 \times 10^{-6}$ \\
ISO 12215-5 & Partial & 4.66 & $2.61 \times 10^{-6}$ \\
\hline
\end{tabular}

